\title{
A search for the evidence supporting community paediatric practice
}

\begin{abstract}
M C J Rudolf, N Lyth, A Bundle, G Rowland, A Kelly, S Bosson, M Garner, P Guest, M Khan, R Thazin, T Bennett, D Damman, V Cove, V Kaur
\end{abstract}

figure has been challenged by a number of disciplines. ${ }^{2-4}$ Claims have been made that $82 \%$ of interventions in inpatient general medicine are evidence based $^{2}$ and $81 \%$ in general practice. $^{3}$

On a recent evidence based paediatric course at the University of Leeds, these figures generated much discussion. "Guestimates" were made as to how clinically effective paediatric practice might be. The hospital paediatricians estimated that $49 \%$ of their work was evidence based, whereas the community paediatricians felt that only $20 \%$ of their work was likely to be so. ${ }^{5}$

The reason behind the community paediatricians' lack of confidence was evident. Community paediatrics has evolved only over the last 20 years to become a consultant led specialty in its own right. As a relative newcomer, it was not likely to have developed the body of research and resources that underpin other specialties.

Therefore, with some apprehension that community paediatrics might prove to be at the bottom of the evidence based medicine league table, the community paediatricians decided to set out to ascertain the evidence base for this specialty.

In planning our study, the limitations of the previous studies were taken into account. ${ }^{2}{ }^{3}$ In these studies, only the primary diagnosis and intervention (determined from retrospective review of notes) had been searched - a limitation of particular importance in the community setting. Moreover, it was not clear that evidence found had been rigorously critically appraised for quality. Finally, an overly broad definition of convincing non-experimental evidence had been used by the general practice paper. $^{2}$

Therefore, our study design was structured so that all aspects of clinical activity undertaken by community paediatricians were studied, and efforts were made to ensure that all evidence was appraised for both quality and relevance to community paediatric patients.

The office of technology assessment of the US Congress published a report in 1978 stating that: "only $10-20 \%$ of all procedures currently

Accepted 19 October 1998 used in medical practice have been shown to be

efficacious by controlled trial". ${ }^{1}$ Since then, this

\section{Methods}

In May 1997, a pilot study was undertaken to highlight any difficulties with data gathering and to develop the format of the clinical diary used. Nine paediatricians recorded every clinical action they undertook on patients over a two day period. From this pilot study, it was determined that there were 10 categories of clinical activity: clinical evaluation, investigations, prescriptions, referrals, monitoring, liaison, counselling/advice (including reassurance), child health promotion, statutory items, and multidisciplinary work. 
Table 2 Numbers of questions posed and clinical actions investigated according to category of clinical activity

\begin{tabular}{|c|c|c|c|c|c|c|c|c|}
\hline \multirow[b]{2}{*}{ Category } & \multirow{2}{*}{$\begin{array}{l}\text { Clinical } \\
\text { evaluation }\end{array}$} & \multirow[b]{2}{*}{ Investigations } & \multirow[b]{2}{*}{ Prescriptions } & \multirow{2}{*}{$\begin{array}{l}\text { Counselling/ } \\
\text { advice }\end{array}$} & \multirow[b]{2}{*}{ Referrals } & \multicolumn{2}{|c|}{ Child health promotion } & \multirow[b]{2}{*}{ Total } \\
\hline & & & & & & Surveillance & Immunisations & \\
\hline Clinical actions (n) & 186 & 63 & 30 & 106 & 72 & 245 & 119 & 821 \\
\hline Questions asked (n) & 17 & 28 & 26 & 17 & 10 & 22 & 20 & 140 \\
\hline $\begin{array}{l}\text { Clinical actions addressed by } \\
\text { questions asked (n) }\end{array}$ & 93 & 53 & 30 & 68 & 24 & 243 & 118 & 629 \\
\hline
\end{tabular}

Questions and searches were not carried out for the following categories: monitoring (174 actions), liaison (132 actions), statutory work (22 actions), and multidisciplinary work (0 actions).

The clinical group for the full study consisted of two consultants, two senior clinical medical officers/associate specialists, one senior registrar, and seven staff grade doctors/ clinical medical officers. The children were seen in a variety of settings: schools/nurseries, special schools, hospital clinics, secondary referral clinics, health centres, child development centres, and at home.

During a two week period in June 1997, the 12 community paediatricians recorded data on every patient they saw during the first four days that they had patient contact. This time scale for recording allowed work done by part-time doctors to be represented as equally as the full timers. Details of all the child's problems and clinical actions taken were recorded and classified according to the categories determined in the pilot study.

Questions were then developed-designed to test the efficacy of the clinical actions. Of the 10 categories, only six were considered to contain clinical actions suitable for posing questions of efficacy and literature searching. An attempt was made to investigate as many of the clinical actions as feasible, focusing on the more frequent and important actions. Evidence for efficacy was then sought by carrying out computerised data searches using MEDLINE, and in some instances CINAHL, psychology, and the Cochrane databases as well. Further evidence was found by hand searching recent articles, obtaining references from relevant articles, consulting experts in the field, and personal communication with colleagues.

Relevant articles identified were critically appraised, using the $\mathcal{F} A M A$ guidelines, ${ }^{6}$ by the individual doing the search. The group then discussed each article both for the quality of the research and its relevance to the patients concerned. The article was graded by consensus according to quality criteria developed by the group (table 1). In all cases where evidence from a good systematic review, a randomised controlled trial or other appropriate design was found (A1 evidence) the article was independ- ently critically appraised by three members of the group. A1 status was only applied if all three agreed that the study was of good design and directly relevant to community paediatrics. Clinical actions were only classified as having convincing non-experimental evidence (A2) if : (1) in the case of prescriptions, a randomised controlled trial with a placebo arm would be unethical; or (2) in the case of clinical evaluation, a study would essentially be impossible, either because the clinical evaluation itself is the gold standard for diagnosis (for example, obesity) or because the definitive study would involve children undergoing hazardous, expensive investigations to ascertain the accuracy of diagnosis, which would also be unethical.

\section{Results}

During the study period, 247 children were seen with 446 problems and a total of 1149 clinical actions were carried out. One hundred and forty questions were posed, which addressed 629 clinical actions. Table 2 shows the numbers of questions by category and the corresponding numbers of clinical actions. Table 3 shows the quality of evidence determined for each category.

There was good evidence from a randomised controlled trial, systematic review, or another appropriate study for $39.9 \%$ of the clinical actions studied, and convincing nonexperimental evidence for $7 \%$. A further $9.7 \%$ of evidence was of good quality but was classed as inconclusive until the research findings could be confirmed in the community paediatric setting. Table 4 details the A1 evidence.

Figure 1 shows the good quality evidence by category. A substantial amount of good quality evidence was found for child health promotion and prescriptions, whereas least evidence was found to support counselling and advice. Even when immunisations were excluded from the analysis of child health promotion, $40 \%$ of actions were graded A1.

Table 3 Quality of evidence found by category of clinical activity

\begin{tabular}{|c|c|c|c|c|c|c|c|}
\hline & $A 1$ & $A 2$ & B1 & $B 2$ & $C$ & $D$ & Total \\
\hline Prescriptions & 16 & 2 & 2 & 4 & 1 & 5 & 30 \\
\hline \multicolumn{8}{|c|}{ Child health promotion } \\
\hline Immunisations & 118 & 0 & 0 & 0 & 0 & 0 & 118 \\
\hline Surveillance & 96 & 0 & 6 & 39 & 0 & 102 & 243 \\
\hline Counselling/advice & 0 & 0 & 9 & 12 & 0 & 47 & 68 \\
\hline Referrals & 7 & 0 & 0 & 6 & 0 & 11 & 24 \\
\hline Investigations & 10 & 0 & 31 & 9 & 0 & 3 & 53 \\
\hline Clinical evaluation & 4 & 42 & 13 & 29 & 0 & 5 & 93 \\
\hline Total (\%) & $251(39.9)$ & $44(7)$ & $61(9.7)$ & $99(15.7)$ & $1(0.2 \%)$ & $173(27.5 \%)$ & $629(100 \%)$ \\
\hline
\end{tabular}

See table 1 for definitions of the different grades of quality of evidence. 
Table 4 Actions supported by evidence from good systematic reviews, randomised controlled trials or good evidence from another appropriate type of study

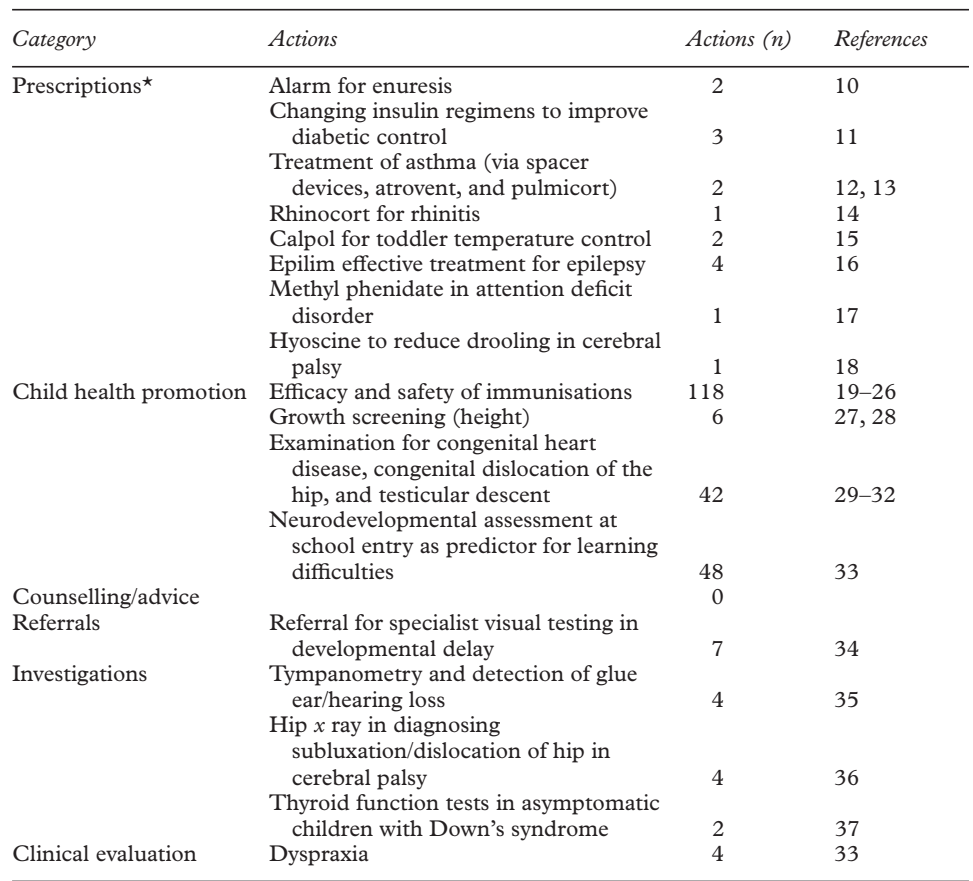

*In addition there was convincing non-experimental evidence for the use of thyroxine in congenital hypothyroidism, and protective helmets for children with problematic epilepsy. There was good evidence of ineffectiveness in prescribing paracetamol to reduce recurrence of febrile fits.

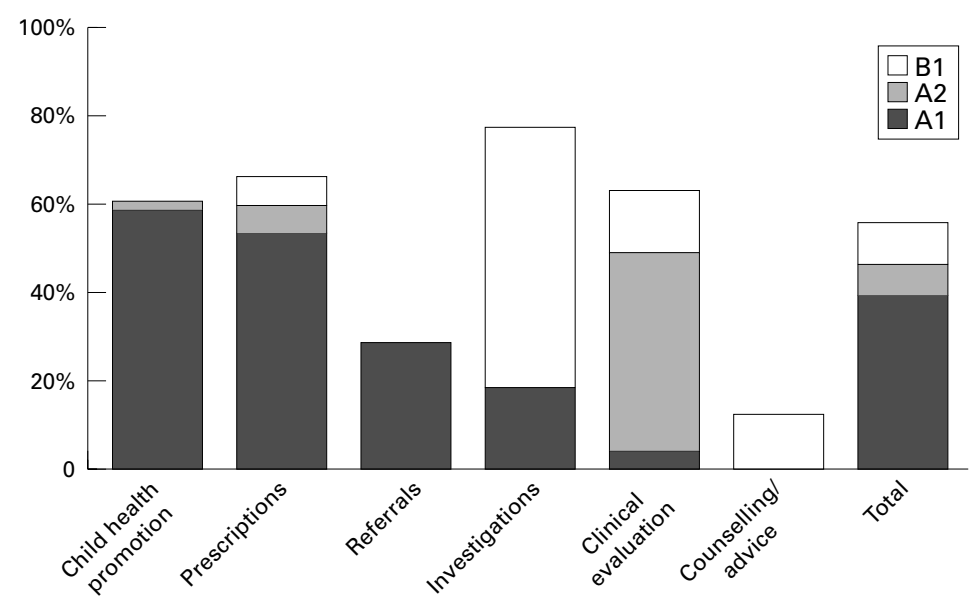

Figure 1 Level of good evidence found for each category of clinical activity. A1, Good quality experimental evidence; A2, Convincing non-experimental evidence; B1, Good evidence but not clearly translatable to the community paediatric patient.

\section{Discussion}

Most of the interventions evaluated in general practice and inpatient general medicine were prescribed medications. Good experimental evidence was found for $53 \%$ of interventions in the general medicine paper ${ }^{2}$ and $31 \%$ of interventions in the general practice paper. ${ }^{3}$ Our study has shown that there is good experimental evidence for $53 \%$ of the prescriptions issued during the study period in community paediatrics. On a very simplistic basis it would be easy to state that there is as much good experimental evidence for community paediatric practice as the other specialties who have studied their evidence base.
However, our study was a refinement on the previously mentioned studies. In our study every clinical action carried out on patients was recorded, not just the action which on review seemed to be the principal one. Second, the quality of the evidence accepted was carefully assessed. Experimental evidence of effectiveness was only accepted if the study was methodologically sound and where the results were directly translatable to patients in a community paediatric setting.

Interestingly, because all clinical actions were recorded in our study, it was apparent that prescriptions accounted for only $3.7 \%$ of clinical actions performed during the study period. Clearly, stating that a specialty is evidence based when only the evidence of the effectiveness of treatments has been considered does not give the whole picture. There should also be clear evidence that diagnostic processes are effective (both clinical evaluation and relevant investigations), and for other components of the consultation, such as advice or reassurance given and referral to other professionals.

Community paediatrics involves more than seeing and treating acutely unwell children and making them well. Child health promotion, counselling and advice, and referral to other professionals are as important. They are included in the calculation that there is good evidence of effectiveness for $47 \%$, and some evidence of effectiveness for a further $25 \%$ of the clinical actions in this community paediatric study.

In some areas disappointingly little evidence was found. Only $4 \%$ of the clinical evaluations made and $19 \%$ of the investigations carried out had clear evidence of accuracy or effectiveness in the community paediatric setting. Furthermore, the study highlighted the difficulties involved in assessing the accuracy of these diagnostic processes where studies would essentially be impossible to design. Further areas lacking in evidence were counselling/advice and referrals to other professionals.

It must be emphasised, however, that absence of evidence is not evidence of ineffectiveness, ${ }^{38}$ and the conclusion should therefore be that further research is required, rather than that these aspects of community paediatric practice are not worthwhile. Monitoring, liaison, multidisciplinary work, and statutory work are also an important part of community paediatrics. They were not evaluated in our study, and it is likely that the effectiveness or value of this type of work may best be answered by qualitative rather than quantitative research methods.

It was clear that overall there was a paucity of evidence from studies that had been carried out in the community or ambulatory paediatric setting. This meant that some good evidence was not given A1 status because we could not deem that the results were applicable to our patients. Examples included studies where counselling had been provided by a psychologist, or clinical evaluations had been carried out by tertiary specialists and where it 
could not be assumed that a community paediatrician would be similarly effective. Much research from hospital settings must be substantiated in the community setting before it can be considered applicable to community paediatricians and our broad spectrum of patients.

It is worthy of mention that so much of the clinical work of community paediatricians (identified by the process of keeping diaries) was found to be very similar to the work conventionally thought to be the province of hospital paediatricians. This suggests that the results of our study might well be extrapolated to the specialty of paediatrics as a whole.

The design of our study, which followed that of the studies in inpatient general medicine and general practice has both strengths and limitations. Using clinical encounters as the basis for searching for evidence ensures that common and important questions are answered. Reassuringly higher levels of evidence were found in all studies based on this design than those figures based on assessments of interventions that are high tech, high profile, and expensive. ${ }^{12}$

However, limitations were identified. Community child health tends to be seasonal and, because all the data collection for our study was carried out towards the end of the academic year, statutory work in school was underrepresented. Also underrepresented, by chance, were child protection and multidisciplinary work, both important aspects of community paediatrics. Our study also highlighted the need to ensure that clinical questions are well thought out and appropriate before searching databases.

Our study emphasises the need to ascertain the evidence underpinning all clinical actions, not simply "principal" interventions, which are often the easiest to search or indeed research. It should also be noted that searching for evidence can be time consuming. In preparing this paper 151 hours were spent doing electronic literature searches alone. It was estimated that these hours would be tripled when the time taken to find the journal articles and appraise them was included. Less than $50 \%$ of the group had access to a database at work or at home, and a number of journeys had to be made to the British Library to retrieve articles from some journals. If evidence based medicine is to become a reality, clinicians need easy access to electronic databases and good library support.

The authors are community paediatricians working in Yorkshire, Manchester, Teesside, and Cheshire. They are all students or staff in the Academic Unit of Paediatrics and Child Health, University of Leeds. This paper was a collaborative effort with all authors contributing to conception, design, analysis, and interpretation of the data; drafting and/or revising the article; and approval of the final version.

1 Office of Technology Assessment of the Congress of the United States. Assessing the efficacy and safety of medical technologies. Washington, DC: US Government Printing technologies.

2 Ellis J, Mulligan I, Rowe J, Sackett DL. Inpatient general medicines is evidence based. Lancet, 1995;346:407-10.
3 Gill P, Dowell AC, Neall RD, Smith N, Heywood P, Wilson AE. Evidence based general practice: a retrospective study AE. Evidence based general practice: a retrospective study
of interventions in one training practice. BMF 1996;312: of inter

4 Kenny SE, Shankar KR, Rintala R, Lamont GL, Lloyd DA. Evidence based surgery: interventions in a regional paediatric surgical unit. Arch Dis Child 1997;76:50-5.

5 Rudolf MC, Jones K. Attitudes to questioning in clinical practice may be changed. $B M \mathcal{F} 1998 ; 316: 1535-6$.

6 Users' guides to the medical literature, II. How to use an article about therapy or prevention. [Guyatt GH, Sackett DL, Cook DJ. Are the results of the study valid? FAMA 1993;270:2598-601. Guyatt GH, Sackett DL, Cook DJ. What were the results and will they help me in caring for my patients? FAMA 1994;272:234-7.]

7 Users' guides to the medical literature, II. How to use an article about a diagnostic test. [Jaeschke R, Guyatt GH, Sackett DL. Are the results of the study valid? $f A M A$ 1994; 271:389-91. Jaeschke R, Guyatt GH, Sackett DL.
. 1994;271:389-91. Jaeschke R, Guyatt GH, Sackett DL.
What are the results and will they help me in caring for my patients? fAMA 1994;271:703-7.]

patients? ' $A M M A 1994 ; 271: 703-7$.
8 Users' guides to the medical literature, VI. How to use an overview. [Oxman AD, Cook DJ, Guyatt GH. FAMA 1994; 272:1367-71.]

9 Users' guides to the medical literature, VII. How to use a clinical analysis. [Richardson WS, Detsky AS. Are the results of the study valid? $\mathcal{F} A M A$ 1995;273:1292-5. Richardson WS, Detsky AS. What are the results and will they help me in caring for my patients? $\mathcal{F} A M A$ 1995;273: 1610-13.]

10 CRD Report 11. Systematic review of the effectiveness of interventions for managing childhood enuresis. University of York. NHS Centre for reviews and disseminations, 1997.

11 Diabetes Control and Complications Trial Research Group. Effect of intensive diabetes treatment on the development and progression of long-term complications in adolescents and progression of long-term complications in adolescents
with insulin-dependent diabetes mellitus: DCCT. $\mathcal{F}$ Pediatr 1994;125:177-88.

12 Clark JR, Aston H, Silverman M. Delivery of salbutamol by metered dose inhaler and valved spacer device to wheezy infants: effect on bronchial responsiveness. Arch Dis Child 1993;69:125-9

13 Gleeson JG, Price JF. Controlled trial of budesonide given by the nebuhaler in preschool children with asthma. BMF 1988;297:163-6.

14 Agertoft L, Wolthers OD, Fuglsang G, Pedersen S. Nasal powder administration of budesonide for seasonal rhinitis in children and adolescents. Pediatr Allergy Immunol 1993;4:152-6.

15 Kinmonth AL, Fulton Y, Campbell MJ. Management of feverish children at home. $B M F$ 1992;305:1134-6.

16 De Silva M, MacArdle B, McGowan M, Hughes E, Stewart J, Neville BG. Randomised comparative trial of phenobarbitone, phenytoin, carbamazepine or sodium valproate for newly diagnosed childhood epilepsy. Lancet 1996;347:70913.

17 Spencer T, Biederman J, Wilens T, Harding M, O'Donnell $\mathrm{D}$, Griffin S. Pharmacotherapy of attention deficit hyperactivity disorder across the life cycle. $\mathcal{F}$ Am Acad Child Adolesc Psychiatry 1996;35:409-32.

18 Lewis DW, Fontana C, Mehallick LK, Everett Y. Transdermal scopolamine for reduction of drooling in developmentally delayed children. Dev Med Child Neurol 1994;36:484-6.

19 Bainton D, Freeman M, Magrath DI. Immunity of children to diphtheria, tetanus and polio. BMF 1979;i:854-7.

20 Booy R, Aitken SJ, Taylor S, et al. Immunogenicity of combined diphtheria tetanus and pertussis vaccine given at 2,3 and 4 months versus 3,5 and 9 months of age. Lancet and 4 months ver

21 Bell F, Maitin A, Blondeau C, Thornton C, Chaplais J, Finn A. Combined diphtheria, tetanus, pertussis and Haemophilus influenzae type $b$ vaccines for primary immunisaion. Arch Dis Child 1996;75:298-303.

22 Jones AE, Johns A, Magrath DI, Melville Smith M, Sheffield F. Durability of immunity to diphtheria, tetanus and polio after 3 dose immunisation schedule completed in the first 8 months of life. Vaccine 1989;7:300-2.

23 Patriarca PA, Sutter RW, Oostvogel PM. Outbreaks of paralytic poliomyelitis. F Infect Dis 1997;175(suppl 1):165-72.

24 Ramsay ME, Miller E, Ashworth LA, Coleman TJ, Rush M, Wright PA. Adverse events and antibody response to accelerated immunisation in term and preterm infants. Arch Dis

Peltola H, Heinonen OP, Valle M, et al. The elimination of indigenous measles mumps and rubella from Finland by a indigenous measles mumps and rubella from Finland by a $1397-402$.

26 Boulianne N, De Serres G, Ratnam S, Ward BJ, Joly JR, Duval B. Measles mumps and rubella antibodies in children 5-6 years after immunisation. Vaccine 1995;13: 1617-22.

27 Ahmed ML, Allen AD, Sharma A, Macfarlane JA, Dunger DB. Evaluation of a district screening programme Oxford growth study. Arch Dis Child 1993;69:361-5.

28 Voss LD, Mulligan J, Betts PR, Wilkin TJ. Poor growth in school entrants as an index of organic disease: the Wessex growth study. BMF 1992;305:1400-2.

29 Stewart C, Stewart M, Craig B, Mulholland C. Does the current approach to screening for congenital heart disease detect it? Ambulatory Child Health 1997;3:115-20.

30 Darmonov AV, Zagora S. Clinical screening for congenital dislocation of the hip. F Bone foint Surg Am 1996;78:383-8. 31 Atwell JD. Ascent of the testis: fact or fiction. Br f Urol 1985;57:474-7. 
32 Robertson JFR, Azony AF, Cochran W. Assent to ascent of the testis. Br F Urol 1988;61:146-7.

33 Haines CR, Brown JB, Grantham EB, Rajagopalan VS, Sutcliffe PV. Neurodevelopmental screen in the school entrant medical examination as a predictor of co-ordination and communication difficulties. Arch Dis Child 1985;60:1122-7.

34 Warburgh MM, Frederekson P, Rattoef J. Blindness among 7700 mentally retarded children in Denmark. In: Clinics in developmental medicine. Cambridge: Cambridge University Press, 1979:567.
35 Dempster JH, Mackenzie K. Tympanometry in the detection of hearing impairment associated with otitis media with effusion. Clin Otolaryngol 1991;16:157-9.

6 Scrutton D, Baird G. Surveillance measures of the hips of children with cerebral palsy. Arch Dis Child 1997;76:3814 .

7 Pueschel SM, Pezzullo JC. Thyroid dysfunction in Down's syndrome. Am f Dis Child 1985;139:636-9.

38 Altman DG, Bland JM. Absence of evidence is not evidence of absence. BMF 1995;311:485.

Iodine, selenium, and joints: Kashin-Beck disease

In parts of China, Siberia, North Korea, and Tibet children and adolescents are prone to a strange joint disease called Kashin-Beck disease (named after those who described it in Siberia in the last century). It is a necrotising osteoarthropathy that affects the fingers, hands, elbows, ankles, and knees, usually starting at between 5 and 15 years of age. The regions in which it occurs have in common the fact that both iodine and selenium are in short supply. Now a study in Tibet (Rodrigo Moreno-Reyes and colleagues. New England fournal of Medicine 1998;339:1112-20; see also editorial by Robert D Utiger. Ibid, 1156-8) has suggested that this combined deficiency could be the cause of the problem.

They studied $5755-15$ year old children in 12 villages; only one village did not have endemic Kashin-Beck disease. Severe selenium deficiency was present in all the villages, mean serum concentrations being some $15-20 \%$ of the lower limit of normal. Almost half of the children studied had Kashin-Beck disease, a similar proportion were goitrous, and two thirds had very low urinary iodine concentrations. The findings that distinguished those with Kashin-Beck disease from those without were low urinary iodine, high serum thyrotropin, and low serum thyroxine binding globulin, but not serum selenium.

Selenium is an important component of two enzymes, glutathione peroxidase and iodothyronine deiodinase. It is postulated that combined deficiency of selenium and iodine could result in tissue oxidative damage because of lack of the first of these enzymes and this together with tissue thyroid hormone deficiency could produce joint damage. The hypothesis seems reasonable although it is as yet unproved.

ARCHIVIST 